\title{
Global trends in insecticide resistance and impact on disease vector control measures
}

This article was published in the following Dove Press journal:

Open Access Insect Physiology

18 July 2011

Number of times this article has been viewed

\section{Rajendra Maharaj}

Malaria Research Unit, Medical Research Council, Durban, South Africa
Correspondence: Rajendra Maharaj PO Box 70380, Overport 4067, South Africa

Tel +27 3I 2034793

Fax +273। 203483 ।

Email rmaharaj@mrc.ac.za
Abstract: For the past 80 years, chemicals have played an important role in vector control programs. Indoor residual spraying and the use of insecticide-treated nets are the main strategies for malaria vector control and they rely heavily on the use of insecticides. However, the development of resistance to the various classes of insecticides has resulted in a reduction of the efficacy of these interventions. Resistance to all classes of insecticides has been found on the African continent, with some insecticide resistance reported from Asia, and Central and South America. The development of resistance to insecticides is mainly due to the fact that public health insecticides are reformulations of insecticides that were previously used for agricultural purposes. The rapid spread of insecticide resistance is a major problem in vector control programs where there are only a finite number of insecticides to select from. The problem is exacerbated by cross resistance between various groups of insecticides which further limits the choice of effective insecticides. In order to identify the earliest emergence of resistance, there needs to be monitoring of resistance on a continual basis. Resistance monitoring is necessary to ensure that effective insecticides are being used and to ensure that changes to insecticide policy are based on sound scientific data. Resistance management strategies need to be implemented from the outset because methods for delaying resistance becomes less effective as resistance becomes common. The advent of resistance has resulted in programs undergoing a paradigm shift from spraying single insecticides to using insecticide combinations and rotational spraying. The main impact of resistance on disease control programs has been the way in which insecticides are applied. Increasing resistance to insecticides has generated an interest in finding new chemical compounds that insecticide vectors are susceptible to. Control programs are now moving to an integrated method of control where chemical and nonchemical measures are being used as complementary measures. However, for the moment, chemicals will continue to be used for vector control but they need to be used with caution and in a manner that does not promote the development of resistance.

Keywords: insecticide resistance, chemicals, vector resistance management

\section{Introduction}

Disease burden is usually reduced by appropriate case management (parasite control) or implementing effective vector control measures. While parasite control targets individuals, vector control helps to protect communities from disease. The most common way of controlling disease vectors is through the use of chemicals that either repel or kill the vectors. Insects are the most common vectors of disease, with fleas and flies spreading some of the more important vector-borne diseases. Among the dipterans, it is usually mosquitoes that are the main transmitters of disease, responsible for spreading diseases such as yellow fever, dengue, and malaria. The public health disease that 
garners most importance in terms of vector control is malaria, and it is from the point of view of malaria vector control that global trends in insecticide resistance will be discussed.

Controlling the vector is the only way that high or moderate transmission can be reduced to low intensity. There are essentially four classes of insecticides that are available for public health purposes, namely, organochlorides, organophosphates, carbamates, and pyrethroids. ${ }^{1}$ The most popular organochlorine used for public health is dichlorodiphenyl-trichloroethane (DDT). Recently, resistance to DDT has emerged in India and Africa, and access to quality DDT has diminished in the last three years. ${ }^{2}$ Organophosphates are not favored for indoor residual spraying purposes because they are highly toxic to mammals and have a short residual life. ${ }^{3}$ Carbamates are the favored alternatives to DDT, but they are more expensive and require semesterly application. ${ }^{4}$ Pyrethroids are widely used for indoor residual spraying and are the only insecticide currently used to impregnate nets. $^{5}$

The World Health Organization global elimination strategy was based on the use of chemicals to eradicate the vector of malaria. ${ }^{6}$ The global eradication program of the 1960s was built on the promise of indoor residual spraying. The strategy recommended the widespread use of DDT in particular to control the vector. ${ }^{7}$ The use of insecticides as the main strategy succeeded in eliminating malaria from large parts of Europe and North America. ${ }^{8}$ After almost 70 years of use, there have been few reports of DDT resistance in mosquito vectors. However, resistance to newer classes of insecticides has been reported after a few years of usage. In South Africa, resistance to pyrethroids developed within five years of this insecticide being used for malaria control purposes. ${ }^{9}$ The reason for this is that most formulations of insecticides used for public health purposes were originally used for agricultural purposes. ${ }^{10}$

Resistance to insecticides usually develops through the improper use of insecticides. Improper use of insecticides usually results from programmatic failure or incorrect usage of insecticides. ${ }^{11}$ Insecticide resistance due to programmatic failure occurs when application of insecticides is not timed correctly and periods of effective residual life does not overlap, resulting in vectors being exposed to lower dosages of insecticides. Control programs that do not monitor for insecticide resistance may result in the use of insecticides to which resistance in the vector populations already exist. Incorrect usage of insecticides may also occur when there is leakage of insecticides from the legitimate vector control program. The distribution of insecticide resistance is not uniformly distributed and usually only depicts areas where data have been collected.

\section{Mechanisms of insecticide resistance}

The rapid spread of insecticide resistance is a major problem for malaria vector control programs and seriously threatens malaria control efforts worldwide. The monitoring of insecticide resistance mechanisms is thus critical to control programs making use of indoor residual spraying with insecticides. ${ }^{12,13}$ In a review by Hemingway and Ranson, ${ }^{14}$ insecticide resistance in major mosquito vectors was reported against DDT, benzene hexachloride/dieldrin, organophosphates, carbamates, and pyrethroid insecticides. The modes of insecticide resistance in mosquitoes are through the enzymatic metabolism of insecticides or through changes in the target sites and proteins that insecticides bind to. ${ }^{12,14}$

Metabolism-based resistance is mediated by three major enzyme groups and can lead to resistance to organochlorines, organophosphates, carbamates, and pyrethroids. ${ }^{15}$ Resistance can be the result of either overexpression of enzymes capable of detoxifying insecticides or of amino acid substitutions within the enzymes, which alter the affinity of the enzyme for the insecticide. The enzyme groups responsible for metabolism-based insecticide resistance are the esterases, glutathione S-transferases, and cytochrome P450 monooxygenases. $^{14}$

Target site resistance is most commonly caused by point mutations within structural genes so that the change in amino acid will reduce the binding of the insecticide without resulting in a loss of the primary function of the target site. Target sites for the development of insecticides include acetylcholinesterase, the gamma aminobutyric acid receptor, and sodium channels of mosquitoes. Modification of these target sites may result in resistance to the organophosphorus, carbamates, organochlorines, and pyrethroid insecticides that act on the nervous system of mosquitoes. ${ }^{14}$

\section{Distribution of insecticide resistance}

Insecticide resistance is becoming more prevalent in many parts of the world due to a reduction in the sensitivity of insect populations to insecticides. ${ }^{14,16}$ Insecticide resistance is becoming an increasing problem for malaria vector control programs because many programs rely heavily on the use of insecticides. ${ }^{17}$ Kerah-Hinzoumbe et al ${ }^{18}$ found that Anopheles gambiae sensu lato was becoming resistant to all classes of insecticides used in mosquito control in Chad. Insecticide resistance was reported by Davidson ${ }^{19}$ in 1956 when resistance 
to dieldrin developed in a population of $A$. gambiae from northern Nigeria. ${ }^{20}$ Pyrethroid resistance has been reported in southern parts of Mozambique since $2000 .{ }^{21}$ Resistance to pyrethroids by the malaria vector A. funestus has been shown in northern regions of KwaZulu-Natal, South Africa. ${ }^{9}$

A. funestus collected from sugarcane fields in southern Mozambique was found to be resistant to deltamethrin, lambda-cyhalothrin, and carbamates, all insecticides that have been used in agriculture. ${ }^{22}$ A. funestus from all localities remained fully susceptible to DDT and malathion, an organophosphorus insecticide. A high level of pyrethroid resistance was detected in A. funestus populations in southern Mozambique. ${ }^{23}$ Strong resistance to permethrin and DDT was found in A. gambiae populations from southern Benin. ${ }^{24}$ A. sacharovi was found to be resistant to 12 insecticides in southern Turkey. ${ }^{25}$

Field studies in Africa, India, Brazil, and Mexico provide persuasive evidence for strong behavioral avoidance of DDT by the primary vector species. This avoidance behavior exhibited when malaria vectors evade insecticides by not entering, or by rapidly exiting, sprayed houses, should raise serious questions about the overall value of current physiological and biochemical resistance tests. ${ }^{26} \mathrm{~A}$ high level of resistance to dieldrin was found in $A$. gambiae in northern Nigeria. ${ }^{19}$ Because $A$. arabiensis shows high levels of resistance to DDT in villages in Ethiopia, changes in the vector control strategies were required to ensure the success of vector control operations. $K d r$ resistance was found to be widespread in Ethiopia. ${ }^{27}$ A. culicifacies and A. subpictus populations in Sri Lanka were found to be resistant to malathion and showed high levels of DDT resistance. ${ }^{17}$ A. funestus from Lake Malawi was found to be resistant to deltamethrin, bendiocarb, and permethrin. ${ }^{28}$ Pyrethroid resistance was observed in A. gambiae, the main malaria vector in eastern Guinea. ${ }^{29}$ High levels of DDT resistance and low levels of resistance to organophosphates, carbamates, and pyrethroid insecticides were shown in field populations of $A$. albimanus in southern Mexico. ${ }^{30}$ DDT resistance and dieldrin resistance have been found in the $A$. annularis, $A$. culicifacies, $A$. stephensi, and $A$. subpictus mosquito species in Punjab Province, Pakistan. ${ }^{31}$

\section{Monitoring insecticide resistance}

In areas where disease transmission is high and where the use of chemical insecticides constitutes the main intervention for vector control, a major intensification of resistance monitoring is urgently needed in order to ensure that effective insecticides are being used and to ensure that the insecticide policy is based on scientific data. Decisions on targeting interventions and insecticide selection are contingent on local data. Due to the mobility of disease vectors, insecticide resistance is not regarded as a country-specific issue but is of importance to adjacent countries and regionally. ${ }^{32}$ Therefore, in an attempt to control and contain the spread of insecticide resistance, a regional (multicountry) cross-border reporting system is needed to inform policy at this level, especially in light of the elimination efforts that many countries have embarked upon.

Country disease control programs should reorient their monitoring component to include resistance monitoring and to coordinate monitoring at the country level. The World Health Organization ${ }^{32}$ recommends that all data should be reported as they are collected and without delay. It is essential that insecticide resistance data should not be withheld prior to publication or dissemination to popular media. Nevertheless, monitoring is a shared responsibility of all agencies, including governments and their partners, participating in the implementation of vector control to make sure that adequate resistance testing (and data reporting) is done in their focus areas. Furthermore, insecticide monitoring data should be inputted into a regional coordinating body that collates all data from the reporting countries and makes decisions as to the harmonization of insecticide policy for the region based on actual field data. This in turn would ensure that the most appropriate insecticide is used to prevent the advent of large-scale insecticide resistance. In addition to this, donor agencies funding indoor residual spraying programs should ensure that the recommended insecticide has been informed by adequate resistance monitoring data.

\section{Strategies to delay resistance}

Due to the diminishing number of effective chemicals for vector control, action must be immediate and pre-emptive when resistance is detected. ${ }^{33}$ Measures to manage insecticide resistance must be implemented from the outset, without waiting for detectable resistance, or proof of control failure because methods for delaying resistance (rotations, combinations, mixtures) become less effective as resistance becomes common. ${ }^{32}$

In order to ensure the sagacious use of insecticides, spray personnel should be trained to spray with care and discrimination, both to prevent waste and reduce selection pressure. This can be further enhanced by targeted spraying to avoid nontransmission areas and ensuring correct delivery of insecticide to target vector in terms of dose, timing, and technique. 
In order to reduce reliance on the use of insecticides and to reduce selection pressure, the methods of vector control need to be diversified. This is the principle of integrated vector control measures where chemical measures are used in conjunction with nonchemical measures. ${ }^{34}$ This decreases the amount of insecticides used in the environment, as well as decreasing the selection pressure due to using insecticides.

The global increase in insecticide resistance has required that the vector control measures be adapted to a changing environment. As a result, the traditional vector control programs which relied on repeated use of the same class of insecticide being sprayed for many years had to make a paradigm shift away from the use of a single insecticide to the use of combinations of insecticides.

\section{Rotations}

The rotational use of insecticides, although not a new strategy, is becoming an important one in the fight against spreading insecticide resistance. Rotation of insecticides has been successfully used in agriculture, ${ }^{35}$ and is thought to have a good record at slowing down the evolution of resistance. The basic premise of rotational use of insecticides is that different classes of insecticides are used in successive years. It is advocated that different classes of insecticides be used, yet one needs to ensure that insecticides to which cross-resistance has been identified are not used in the strategy. The cost of insecticides used in a rotation system will obviously vary from year to year, and program managers should ensure that the budget allocated is sufficient to procure insecticides in order to ensure that spray coverage of at least $80 \%$ is attained.

\section{Insecticide combinations}

This is a more recent strategy built on the methodology promulgated by the rotational use of insecticides. This is a combination of single insecticide spraying and rotation. An intervention utilizing insecticide combinations requires that different insecticide classes are applied in different forms within a structure. An example of this technique is the use of a carbamate-treated wall lining and use of a long-lasting net impregnated with a pyrethroid. ${ }^{36} \mathrm{~A}$ vector control strategy using an insecticide combination works on the same principle as that of combination therapy whereby insect vectors that survive exposure to one of the insecticides will be killed by the second insecticide. ${ }^{32}$ This technique of insecticide utilization has not been rolled out on a large scale, but studies investigating the use of combinations have produced very promising results. However, unlike conventional indoor residual spraying and rotational spraying, the cost of utilizing an intervention reliant on indoor residual spraying and insecticide-impregnated nets is a very costly exercise. As with the choice of insecticide for rotational spraying, insecticide combinations need to be carefully chosen to ensure that vectors are not resistant to both classes of insecticides through $k d r$ resistance. Therefore, in areas with high bed net coverage, pyrethroids should not be used.

\section{Insecticide mixtures}

A further adaptation to traditional indoor residual spraying is the use of insecticide coformulations of two insecticides of different classes with a similar rate of decay. ${ }^{32}$ This would ensure that both formulations are present in the effective concentrations to cause vector mortality. This strategy uses the same principle as that of insecticide combinations, in that vectors surviving exposure to one insecticide would succumb to the second insecticide in the formulation. Thus, this would be one of the most effective resistance management approaches because vectors resistant to one class of insecticide will be killed by the coformulation. This also reduces selection pressure on the vector because it is exposed to two different insecticides simultaneously. Unfortunately, the current situation is such that there are no insecticide mixtures available for use in public health, and only a few such products are being used in the agricultural sector. $^{32}$

\section{Impact of resistance}

The impact of resistance is not always clearly visible. For instance, detection of $k d r$ resistance is not followed by control failure. This is most apparent in areas where there is $k d r$ resistance but the introduction of long-lasting insecticidal nets still succeeds in reducing malaria transmission. In order to detect resistance, one needs to be continually looking for it. In recent times, a number of studies have reported increasing levels of insecticide resistance in all classes of insecticides. ${ }^{37}$ This has refocused attention on the production of chemicals that are efficient and cost-effective.

Increasing levels of resistance to the insecticides currently available has generated interest in finding new chemical compounds that vectors are susceptible to. In order to contend with the immediate crisis, new classes of insecticides are needed. ${ }^{32}$ There is also a need for new insecticides in the future because we need to have mechanisms in place to replace insecticide classes as resistance to the insecticides develops. Manufacturers are also searching for new formulations of the 
currently available insecticides in order to address the current need for resistance management tools. ${ }^{32}$ An important requisite is the ability to measure when an insecticide will become ineffective long before the vectors develop resistance to the particular insecticide. In order to stimulate the development of new formulations of insecticides or new classes of insecticides, manufacturers need to know that products which are effective in this way will be favored during the country's insecticide procurement process.

In terms of searching for new chemical compounds with appropriate insecticidal activity, insecticide manufacturers need to form strategic partnerships with research organizations and academics. One public-private partnership to support market development of new products already exists, but other institutional interventions may also be needed..$^{38}$ The Innovative Vector Control Consortium has succeeded in identifying new formulations of insecticide that may be useful in reversing insecticide resistance. While the development of new products for indoor residual spraying is underway, ${ }^{38}$ prospects for new insecticides for long-lasting insecticide-treated nets are less promising. Only through a concerted effort by chemical manufacturers will a wider range of insecticides be developed for impregnating bed nets.

The most important requirement for implementing resistance mitigation strategies is the availability of sustainable financial resources. Changing from traditional or conventional malaria control strategies will require additional expenditures in the form of more expensive insecticides or the cost due to additional spray rounds. ${ }^{4}$ Furthermore, in order to maintain long-term effectiveness of vector control, especially in those countries targeting elimination, shortterm costs will go up. However, in the medium to long term, investing in sustainability of vector control will not only be cost-effective but would result in decreasing morbidity and mortality. Interventions using long-lasting nets would most certainly be cost-saving, if the effectiveness of pyrethroids on these nets is preserved. ${ }^{32}$

Developing a new class of insecticides takes $10-15$ years, and manufacturers will only invest in the research and development of such an insecticide if there are clear prospects of a market that will provide a return on their investment. The major insecticide manufacturers are the only ones who have the resources to search for new molecules. These investors are already constrained by the apparent instability of the public health market which only accounts for some $12 \%$ of all insecticides sold. National and regional malaria control programs need to engage in forward planning to produce a realistic estimate of the insecticide needed to reassure insecticide manufacturers of a continued reliance on insecticides. Donors also need to commit to supporting chemical-based interventions for the long term. ${ }^{32}$

\section{Need for chemicals for vector control}

From the earliest days of malaria control, the use of chemicals has played a leading role in reducing malaria transmission. ${ }^{39}$ Attempts at controlling the larval stages of mosquito vectors started with the use of Paris Green (an oil) which formed a monolayer on the surface of the breeding site and smothered the larvae.$^{40}$ Early attempts at the use of chemicals started with the use of a sulfur-kerosene mixture which was quickly replaced by a pyrethrum-kerosene mixture. This gave rise to traditional indoor residual spraying with DDT. ${ }^{41}$ The global eradication program of the 1960s was built on the promise of achieving effective control of mosquitoes through the use of DDT in indoor residual spraying programs. The elimination program proved to be highly successful in parts of Europe and the US. On the African continent, this initiative failed to have the desired impact due to rapid development of resistance by the vectors to the insecticides that were used. This effectively halted the idea of malaria elimination on the African continent. It is only recently, after 50 years, that elimination is once again being attempted ${ }^{42}$ utilizing a diverse array of tools, most of which are heavily reliant on the use of chemicals.

In the past two decades, insecticide-treated nets have increased in popularity. It was realized that the effectiveness of untreated nets could be improved through the use of chemicals which either killed or repelled insect vectors. ${ }^{43}$ First came treated nets that could be reimpregnated with insecticides every six months. This was not very popular because the nets became ineffective after a few washes and reimpregnation was quite laborious. This led to the development of nets wherein the chemicals were bonded to the fiber of the net, resulting in long-lasting nets which were proclaimed to last five years under field conditions. Although the chemical survives this period, the net is thought to last for only three years. ${ }^{44}$

Because insecticide resistance is impacting negatively on disease control programs, monitoring of insecticide resistance will be a major activity in the next few years. An intensification of efforts in monitoring insecticide resistance will ensure that resistance is detected at the start, when it is still localized. ${ }^{45}$ Most resistance management methods 
are effective only when resistance is rare, not when it has become widespread among the vector population. ${ }^{33}$ One of the expected benefits of resistance management is that the switching of insecticides may allow back-selection against resistance. Although resistance mechanisms have been well studied, the distribution of insecticide resistance has not received much attention, and studies that report on insecticide resistance usually provide evidence from pockets where entomologists have conducted studies. Although the history of resistance is well documented spatiotemporally, monitoring systems need to be put in place to highlight problem areas for intense scrutiny. ${ }^{6}$

In response to the elimination strategies being implemented in a number of countries, ${ }^{6}$ the epidemiology of malaria is being monitored at the lowest level and control failure of interventions dependent on chemicals will be automatically tracked. One of the most serious public health risks identified for insecticide resistance resulting in control failure is a dramatic increase in childhood mortality because acquired immunity would have waned after several years of intensive vector control. Therefore, it is imperative that managers of vector control programs ensure the success of their vector control interventions because the failure to sustain the effectiveness of vector control could result in a major loss of life, as well as in disillusion and mistrust of disease control programs as a whole.

Maintaining effective vector control despite the threat of insecticide resistance will be a significant boost to confidence and will inform and guide current or potential elimination agendas, ${ }^{6}$ ensuring that all decisions are based on scientific data obtained from the field at all levels of control.

\section{Conclusion}

Global trends in the development and spread of insecticide resistance are reviewed. At a global level, the African continent is the worst affected area in terms of insecticide resistance because resistance to all classes of insecticide has been detected on the continent. Due to the unavailability of new chemical compounds to use for indoor residual programs, novel strategies need to be designed to mitigate the impact of insecticide resistance on disease vector control programs. These strategies still require the continued use of insecticides, but used in either combinations, mixtures, or rotationally. There are some public-private partnerships that have been established to develop new insecticides or new formulations of insecticides. Until newer technologies or chemicals are developed, existing chemicals should be used in a manner that does not promote the development of resistance.

\section{Disclosure}

The author reports no conflicts of interest or financial interests in this work.

\section{References}

1. World Health Organization. WHO recommended insecticides for indoor residual spraying against malaria vectors. 2009. Available from: http:// www.who.int/whopes/Insecticides_IRS_Malaria_09.pdf. Accessed 2011 May 17.

2. Van der Berg H. Global status of DDT and its alternatives for use in vector control to prevent disease. Environ Health Perspect. 2009; 11 : $1656-1663$.

3. Freed VH, Schmedding D, Kohnert R, Haque R. Physical chemical properties of several organophosphates: some implication in environmental and biological behaviour. Pestic Biochem Physiol. 1979;10:203-211.

4. Walker K. Cost-comparison of DDT and alternative insecticides for malaria control. Med Vet Entomol. 2000;14:345-354.

5. Najera JA, Zaim M. Decision making criteria and procedures for the judicious use of insecticides. World Health Organization. 2003. Available from: http://whqlibdoc.who.int/hq/2003/WHO_CDS_ WHOPES_2002.5_Rev.1.pdf. Accessed 2011 May 13.

6. Roll Back Malaria. The Global Malaria Action Plan. 2008. Available from: http://www.rollbackmalaria.org/gmap/gmap.pdf. Accessed 2011 May 6.

7. World Health Organization. Implementation of indoor residual spraying of insecticides for malaria control in the WHO African region: Report 2007. Available from: http://www.afro.who.int/index.php?option=com docman\&task=doc_download\&gid=137. Accessed 2011 May 13.

8. Roberts DR, Manguin S, Mouchet J. DDT house spraying and re-emerging malaria. Lancet. 2000;356:330-332.

9. Hargreaves K, Koekemoer LL, Hunt RH, Brooke BD, Mthembu J, Coetzee M. Anopheles funestus resistant to pyrethroid insecticides in South Africa. Med Vet Entomol. 2000;14:181-189.

10. Diabate A, Baldet T, Chandre F, et al. The role of agricultural use of insecticides in resistance to pyrethroids in Anopheles gambiae s.1. in Burkina Faso. Am J Trop Med Hyg. 2002;67:617-622.

11. Brogdon WG, McAllister JC. Insecticide resistance and vector control. Emerg Infect Dis. 1998;4:605-613.

12. Hemingway J, Field L, Vontas J. An overview of insecticide resistance. Science. 2002;298:96-97.

13. Casimiro S, Coleman M, Hemingway J, Sharp B. Insecticide resistance in Anopheles arabiensis and Anopheles gambiae from Mozambique. J Med Entomol. 2006;43:276-282.

14. Hemingway J, Ranson H. Insecticide resistance in insect vectors of human disease. Annu Rev Entomol. 2000;45:371-391.

15. Nauen R. Insecticide resistance in disease vectors of public health importance. Pest Manag Sci. 2007;63:628-633.

16. Munhenga G, Masendu HT, Brooke BD, Hunt RH, Koekemoer LK. Pyrethroid resistance in the major malaria vector Anopheles arabiensis from Gwave, a malaria endemic are in Zimbabwe. Malar J. 2008;7: 247-258.

17. Devika M, Perera B, Hemingway J, Karunaratne SHPP. Multiple insecticide resistance mechanisms involving metabolic changes and insensitive target sites selected in anopheline vectors of malaria in Sri Lanka. Malar J. 2008;7:168-178.

18. Kerah-Hinzoumbe C, Peka M, Nwane P, et al. Insecticide resistance in Anopheles gambiae from South western Chad, Central Africa. Malar J. 2008;7:192-201.

19. Davidson G. Insecticide resistance in Anopheles gambiae Giles: a case of simple Mendelian inheritance. Nature. 1956;178:863-864.

20. Brooke BD, Kloke G, Hunt RH, et al. Bioassay and biochemical analyses of insecticide resistance in southern Africa Anopheles funestus (Diptera: Culicidae). Bull Entomol Res. 2001;91:265-272.

21. Cuamba N, Morgan JC, Irving H, Steven A, Wondji CS. High level of pyrethroid resistance in an Anopheles funestus population of the Chokwe District in Mozambique. PLoS One. 2010;5:e11010. 
22. Kloke RG, Nhamahanga E, Hunt RH, Coetzee M. Vectorial status and insecticide resistance of Anopheles funestus from a sugar estate in southern Mozambique. Parasit Vectors. 2011;9:4-16.

23. Casimiro S, Coleman M, Mohloai P, Hemingway J, Sharp B. Insecticide resistance in Anopheles funestus (Diptera: Culicidae) from Mozambique. J Med Entomol. 2006;43:267-275.

24. Yadouleton AW, Padonou G, Asidi A, et al. Insecticide resistance status in Anopheles gambiae in southern Benin. Malar J. 2010;9:83-89.

25. Kasap H, Kasap M, Alptekin D, Luleyap U, Herath PRJ. Insecticide resistance in Anopheles sacharovi Favre in Southern Turkey. Bull World Health Organ. 2000;78:687-692.

26. Roberts DR, Andre RG. Insecticide resistance issues in vector-borne disease control. Am J Trop Med Hyg. 1994;50(Suppl 6):21-34.

27. Balkew M, Ibrahim M, Koekemoer LL, et al. Insecticide resistance in Anopheles arabiensis (Diptera: Culicidae) from villages in central, northern and south west Ethiopia and detection of $k d r$ mutation. Parasit Vectors. 2010;3:40-46

28. Hunt R, Edwardes M, Coetzee M. Pyrethroid resistance in southern African Anopheles funestus extends to Likoma Island in Lake Malawi. Parasit Vectors. 2010;3:122-126.

29. Carnevale P, Toto JC, Guibert P, Keita M, Manguin S. Entomological survey and report of a knockdown resistance mutation in the malaria vector Anopheles gambiae from the Republic of Guinea. Trans $R$ Soc Trop Med Hyg. 2010;104:484-489.

30. Penilla RP, Rodríguez AD, Hemingway J, Torres JL, Arredondo-Jiménez JI, Rodríguez MH. Resistance management strategies in malaria vector mosquito control - Baseline data for a large-scale field trial against Anopheles albimanus in Mexico. Med Vet Entomol. 1998;12:217-233.

31. Rathor HR, Toqir G, Reisen WK. Status of insecticide resistance in anopheline mosquitoes of Punjab Province, Pakistan. Southeast Asian J Trop Med Public Health. 1980;11:332-340.

32. World Health Organization. The technical basis for coordinated action against insecticide resistance: Preserving the effectiveness of modern malaria vector control. 2010. Available from: http://www.who.int/malaria/ publications/atoz/9789241501095/en/index.html. Accessed 2011 May 13.

33. Insecticide Resistance Action Committee. Prevention and management of insecticide resistance. In: Vectors of public health importance. Available from: http://www.irac-online.org/resources-2/documentlibrary/. Accessed 2011 May 6.
34. International POPs Elimination Network Pesticide Working Group. DDT and malaria. Available from: http://www.ipen.org/ipenweb/ documents/work\%20documents/ddt_ipenreport_english.pdf. Accessed 2011 May 13.

35. Razaq M, Suhail A, Arif MJ, Aslam M, Sayyed AH. Effect of rotational use of insecticides on pyrethroids resistance in Helicoverpa armigera (Lep: Noctuidae). J Appl Entomol. 2007;131:460-465.

36. Djènontin A, Chabi J, Baldet $\mathrm{T}$, et al. Managing insecticide resistance in malaria vectors by combining carbamate-treated plastic wall sheeting and pyrethroid-treated bed nets. Malar J. 2009;8:233.

37. Southern Region Integrated Pest Management Center and the Insecticide Resistance Action Committee. Mode of Action Initiative. Insecticide resistance: causes and actions. Available from: http://www.sripmc.org/ IRACMOA/IRMFactSheet.pdf. Accessed 2011 May 19.

38. Innovative Vector Control Consortium. IVCC develops new public health insecticides. Available from: http://www.ivcc.com. Accessed 2011 May 19.

39. Centers for Disease Control and Prevention. Eradication of malaria in the United States (1947-1951). 2004. Available from: http://www.cdc. gov/malaria/history/eradication_us.htm. Accessed 2011 May 6.

40. Russell P. Automatic distribution of Paris Green for malaria control. J Parasitol Res. 1933;19:215-224.

41. Buxton PA. The use of the new insecticide DDT in relation to the problems of tropical medicine. Trans R Soc Trop Med Hyg. 1945;38: $367-400$.

42. Feachem RGA, Phillips AA, Targett GA. Shrinking the Malaria Map: A Prospectus on Malaria Elimination. 1st ed. San Francisco, CA: The Global Health Group, Global Health Sciences, University of California; 2009.

43. Lines J, Addington W. Insecticide-treated nets in Tanzania. Lancet 2001;358-371.

44. Masum H, Shah R, Schroeder K, Daar AS, Singer PA. Africa's largest long-lasting insecticide-treated net producer: lessons from A to Z textiles. BMC Int Health Hum Rights. 2010;10 (Supp1 1):S6.

45. Kelly-Hope L, Ranson H, Hemingway J. Lessons from the past: Managing insecticide resistance in malaria control and eradication programmes. Lancet Infect Dis. 2008;8:387-389.

\section{Publish your work in this journal}

Open Access Insect Physiology is an international, peer-reviewed, open access journal publishing original research, reports, reviews and commentaries on all areas of insect physiology. The manuscript management system is completely online and includes a very quick and fair peer-review system, which is all easy to use.

\section{Dovepress}

Visit http://www.dovepress.com/testimonials.php to read real quotes from published authors. 